Pacific Journal of Mathematics

OSCILLATORY PROPERTIES OF SOLUTIONS OF CERTAIN
$n$ TH ORDER FUNCTIONAL DIFFERENTIAL EQUATIONS

GARY GReFsRL 


\section{OSCILLATORY PROPERTIES OF SOLUTIONS OF CERTAIN $n$th ORDER FUNCTIONAL DIFFERENTIAL EQUATIONS}

\section{GARY W. GREFSRUd}

With $n$ even and $\int^{\infty} t^{n-1} a(t) d t<\infty$, necessary conditions for $x^{(n)}(t)+a(t) f(x(g(t)))=0$ to have a bounded nonoscillatory solution are given. If $\boldsymbol{n}=2$, sufficient conditions are also given. Conditions which insure that solutions of $x^{(n)}(t)+$ $f(t, x(g(t)))=0$ are oscillatory or tend monotonically to zero are also presented in this paper.

Let $g(t)$ and $f(t, y)$ be real valued functions. In this paper we prove several oscillation theorems associated with solutions of the following two $n$th order functional differential equations:

$$
\begin{aligned}
& x^{(n)}(t)+a(t) f(x(g(t)))=0, \quad \text { and } \\
& x^{(n)}(t)+f(t, x(g(t)))=0 .
\end{aligned}
$$

We use the "normal" definition of oscillatory, that is, $x(t)$ is an oscillatory solution of (1) or (2) if $x(t)$ satisfies (1) or (2) for large $t$ and $x(t)$ has arbitrarily large zeros $(x(t) \not \equiv 0)$.

Theorems 4 and 5 are generalizations of results proved by Ryder and Wend [6], associated with the equation $x^{(n)}+f(t, x)=0$. In fact the proof of theorem 5 has been omitted because of its similarity with the corresponding result in [6].

Before stating our main results we give the following lemmas.

LEMMA 1. Suppose $f(t) \in C^{k}[a, \infty), f(t) \geqq 0$ and $f^{(k)}(t)$ is monotone. Then exactly one of the following is true:

(i) $\lim _{t \rightarrow \infty} f^{(k)}(t)=0$,

(ii) $\lim _{t \rightarrow \infty} f^{(k)}(t)>0$ and $f(t), \cdots, f^{(k-1)}(t)$ tend to $\infty$ as $t \rightarrow \infty$.

LEMMA 2. If $y(t) \in C^{n}[a, \infty), y(t) \geqq 0$ and $y^{(n)}(t) \leqq 0$ on $[a, \infty)$, then exactly one of the following is true:

(I) $y^{\prime}(t), \cdots, y^{(n-1)}(t)$ tend monotonically to zero as $t \rightarrow \infty$.

(II) There is an odd integer $k, 1 \leqq k \leqq n-1$, such that $\lim _{t \rightarrow \infty} y^{(n-j)}(t)=0$ for $1 \leqq j \leqq k-1, \lim _{t \rightarrow \infty} y^{(n-k)}(t) \geqq 0, \lim _{t \rightarrow \infty} y^{(n-k-1)}(t)>$ 0 and $y(t), y^{\prime}(t), \cdots, y^{(n-k-2)}(t)$ tend to $\infty$ as $t \rightarrow \infty$. 

$[a, \infty)$.

Analogous statements can be made if $y(t) \leqq 0$ and $y^{(n)}(t) \geqq 0$ on

The results of Lemma's 1 and 2, given in [6], will be used throughout this paper.

THEOREM 1. Suppose that $n$ is even and

(i) $\quad a(t) \geqq 0$ for $t$ sufficiently large,

(ii) $\lim _{t \rightarrow \infty} g(t)=+\infty$,

(iii) $y f(y)>0(y \neq 0), f(y)$ continuous on $(-\infty, \infty)$.

Then a necessary condition for equation (1) to have a bounded nonoscillatory solution is $\int^{\infty} t^{n-1} a(t) d t<\infty$.

Proof. Let $x(t)$ be a bounded nonoscillatory solution of (1). Suppose $x(t)>0$ for $t$ sufficiently large. Thus, since $\lim _{t \rightarrow \infty} g(t)=+\infty$, we have that $x(g(t))>0$ for $t$ sufficiently large. Hence, pick $T$ large enough so that $a(t) \geqq 0, x(t)>0$ and $x(g(t))>0$ for $t \geqq T$. We have (for $t \geqq T$ ), using Lemma $2, x^{(n-1)}(t) \geqq 0$,

$$
x^{(n-2)}(t) \leqq 0, \cdots, \dot{x}(t) \geqq 0: \lim _{t \rightarrow \infty} x^{(t)}(t)=0, \quad i=1, \cdots, n-1
$$

Thus, $x(t)$ is a nondecreasing function and since $x(t)>0$ and is bounded we have, $\lim _{t \rightarrow \infty} x(t)=\lim _{t \rightarrow \infty} x(g(t))=L>0$.

From (1),

$$
x^{(n-1)}(s) \geqq \int_{s}^{\infty} a(u) f(x(g(u))) d u
$$

An integration of (3) $n-2$ times from $t$ to $\infty$ yields

$$
(-1)^{n} \dot{x}(t) \geqq \int_{t}^{\infty} \frac{(u-t)^{n-2}}{(n-2) !} a(u) f(x(g(u))) d u
$$

and integrating (4) from $s$ to $t$ where $T \leqq s \leqq t$ we have

$$
x(t)-x(s) \geqq \int_{s}^{t} \frac{(u-s)^{n-1}}{(n-1) !} a(u) f(x(g(u))) d u .
$$

Now using the continuity of $f$ we may choose $T_{1} \geqq T$ such that for $t \geqq T_{1}$, $f(x(g(t))) \geqq \frac{1}{2} f(L)=M$. Hence for $T \leqq T_{1} \leqq s \leqq t$. we have

$$
x(t)-x(s) \geqq \frac{M}{(n-1) !} \int_{s}^{t}(u-s)^{n-1} a(u) d u .
$$


Letting $t \rightarrow \infty$ in (5) we have

$$
\int_{s}^{\infty}(u-s)^{n-1} a(u) d u<\infty
$$

Then for $t \geqq 2 s$ we have

$$
\int_{t}^{\infty}\left(\frac{u}{2}\right)^{n-1} a(u) d u<\int_{t}^{\infty}(u-s)^{n-1} a(u) d u<\infty
$$

i.e. $\int_{t}^{\infty} u^{n-1} a(u) d u<\infty$.

If $x(t)<0$ for $t$ sufficiently large a similar proof yields the desired result. Q.E.D.

When $n=2$, we establish sufficient conditions for equation (1) to have a bounded nonoscillatory solution.

THEOREM 2. With $n=2$ and

(i) there exists $t_{1}>0$ such that $g(t) \geqq t_{1}$ for all $t \geqq t_{1}$,

(ii) $g(t)$ is continuous on $[0, \infty)$,

(iii) $f(y)$ is continuous on $(-\infty, \infty)$ with $y f(y)>0$ for $y \neq 0$,

(iv) $\left|f\left(y_{1}\right)\right| \leqq\left|f\left(y_{2}\right)\right|$ if $\left|y_{1}\right| \leqq\left|y_{2}\right|$,

(v) for each $\beta>0$, there is a $t>0$ that satisfies the inequality $f(t) \leqq \beta t$,

(vi) $a(t) \geqq 0$ and locally integrable on $[0, \infty)$ with $a(t)$ not identically zero on any subinterval of $[0, \infty)$, if

$$
\int^{\infty} t a(t) d t<\infty
$$

then there exists a bounded nonoscillatory solution of (1).

Proof. Assuming that $\int^{\infty} t a(t) d t<\infty$, we note that $(v)$ implies the existence of some number $M>0$ such that

$$
\int_{t_{1}}^{\infty} s a(s) d s \leqq \frac{M}{2 f(M)}
$$

where $t_{1}$ is chosen to satisfy (i). Consider now the integral equation

$$
x(t)=\frac{M}{2}+t \int_{t}^{\infty} a(s) f(x(g(s))) d s+\int_{t_{1}}^{t} s a(s) f(x(g(s))) d s .
$$


We now define a sequence $\left\{x_{k}(t)\right\}$ by

$$
\begin{aligned}
x_{0}(t)= & \frac{M}{2} \\
x_{k}(t)= & \frac{M}{2}+t \int_{t}^{\infty} a(s) f\left(x_{k-1}(g(s))\right) d s \\
& +\int_{t_{1}}^{t} s a(s) f\left(x_{k-1}(g(s))\right) d s .
\end{aligned}
$$

One concludes that $x_{k}(t), k=0,1,2, \cdots$, is defined and continuous and, in fact, is positive on $\left[t_{1}, \infty\right)$. By induction we have

$$
\begin{aligned}
& \frac{M}{2} \leqq x_{k}(t) \leqq M, \quad k=0,1,2, \cdots, \quad \text { and } \\
& x_{k}(t) \geqq x_{k-1}(t) .
\end{aligned}
$$

Thus the sequence $\left\{x_{k}(t)\right\}$ converges to some function $x(t)$ for $t \geqq t_{1}$ and indeed

$$
\frac{M}{2} \leqq x(t) \leqq M\left(\frac{M}{2} \leqq x(g(t)) \leqq M\right)
$$

for $t \geqq t_{1}$.

We now must establish that $x(t)$ is a solution of the integral equation (8) and thus a solution (nonoscillatory) of (1). For any $\epsilon>0$, choose $T$ large enough so that $\int_{T}^{\infty} s a(s) d s<\epsilon / 2 f(M)$. Then we have

$$
\begin{aligned}
\mid x_{k}(t) & -\frac{M}{2}-t \int_{t}^{\infty} a(s) f(x(g(s))) d s-\int_{t_{1}}^{t} s a(s) f(x(g(s))) d s \mid \\
\leqq & t \int_{t}^{\infty} a(s)\left|f\left(x_{k-1}(g(s))\right)-f(x(g(s)))\right| d s \\
& \quad+\int_{t_{1}}^{t} s a(s)\left|f\left(x_{k-1}(g(s))\right)-f(x(g(s)))\right| d s \\
\leqq & \int_{t}^{T} s a(s)\left|f\left(x_{k-1}(g(s))\right)-f(x(g(s)))\right| d s \\
& \quad+\int_{t_{1}}^{t} s a(s)\left|f\left(x_{k-1}(g(s))\right)-f(x(g(s)))\right| d s \\
& \quad+\int_{T}^{\infty} s a(s) f\left(x_{k-1}(g(s))\right) d s+\int_{T}^{\infty} s a(s) f(x(g(s))) d s \\
\leqq & \int_{t_{1}}^{T} s a(s)\left|f\left(x_{k-1}(g(s))\right)-f(x(g(s)))\right| d s+\epsilon .
\end{aligned}
$$


Letting $k \rightarrow \infty$ we obtain

$$
\left|x(t)-\frac{M}{2}-t \int_{t}^{\infty} a(s) f(x(g(s))) d s-\int_{t_{1}}^{t} s a(s) f(x(g(s))) d s\right| \leqq \epsilon .
$$

Thus $x(t)$ is a bounded nonoscillatory solution of (1). Q.E.D.

Restricting our attention now to equation (2), we make the following assumptions:

(i) $g(t) \geqq t-c$ for $t$ sufficiently large, $c>0$, constant,

(ii) $f(t, y)$ is continuous in $S=[0, \infty) x(-\infty, \infty)$,

(iii) $a(t) \Phi(y) \leqq f(t, y)$ if $y>0$ and $f(t, y) \leqq b(t) \psi(y)$ if $y<0$, $(t, y) \in S$, where

(iv) $a(t)$ and $b(t)$ are nonnegative and locally integrable on $[0, \infty)$ and neither $a(t)$ nor $b(t)$ is identically zero on any subinterval of $[0, \infty)$,

(v) $\Phi(y)$ and $\psi(y)$ are nondecreasing with $y \Phi(y)>0$ and $y \psi(y)>$ 0 on $(-\infty, \infty)$ for $y \neq 0$.

(vi) there exist positive constants $\beta$ and $\delta$ such that $\Phi(\lambda y)=$ $\lambda^{\beta} \Phi(y), \psi(\lambda y)=\lambda^{\delta} \psi(y), \lambda$ constant,

(vii) for some $\alpha>0$

$$
\int_{\alpha}^{\infty} \frac{d u}{\Phi(u)}<\infty \quad \text { and } \quad \int_{-\alpha}^{-\infty} \frac{d u}{\psi(u)}<\infty
$$

THEOREM 3. Let $x(t)$ be a solution of (2), valid for large $t$, which is nonoscillatory. If $n$ is odd, assume $\lim _{t \rightarrow \infty} x(t) \neq 0$. Suppose conditions (i)-(vi) of (12) are satisfied. Then there exists a positive number $k$ such that $\Phi(x(g(t))) / \Phi(x(t)) \geqq k$ if $x(t)$ is eventually positive and $\psi(x(g(t))) / \psi(x(t)) \geqq k$ if $x(t)$ is eventually negative for $t$ sufficiently large.

Proof. Let $x(t)$ be a nonoscillatory solution of (2). Suppose $x(t)>0$ for $t$ sufficiently large. Pick $T$ large enough so that $x(t-c)>0$ for $t \geqq T$. From (2) we have

$$
x^{(n)}(t)=-f(t, x(g(t))) \leqq-a(t) \Phi(x(g(t))) \leqq 0 \quad \text { if } \quad t \geqq T .
$$

Thus from Lemmas 1 and 2, $x(t)$ satisfies one of the following:

(1) $\ddot{x}(t) \geqq 0, \dot{x}(t) \leqq 0$ for $t$ sufficiently large,

$$
\lim _{t \rightarrow \infty} \dot{x}(t)=0, \quad \lim _{t \rightarrow \infty} x(t)=L>0 .
$$

(2) $\ddot{x}(t) \leqq 0, \dot{x}(t) \geqq 0$ for $t$ sufficiently large. 
(3) $\ddot{x}(t) \geqq 0, \quad \dot{x}(t) \geqq 0 \quad$ for $t$ sufficiently large, with $x(t), \dot{x}(t), \cdots, x^{(n-k-2)}(t)$ tending to $\infty$ as $t \rightarrow \infty, x^{(n-k-1)}(t)$ increasing to $L$ $(0<L \leqq \infty), \quad x^{(n-k)}(t) \quad$ decreasing to $M(M \geqq 0)$, and $x^{(n-k+1)}(t)$, $\cdots, x^{(n-1)}(t)$, tending to zero as $t \rightarrow \infty$.

If case (1) applies we trivially have $x(g(t)) / x(t) \geqq \frac{1}{2}$ for $t$ sufficiently large.

In either case (2) or (3) we have, since $\dot{x}(t) \geqq 0, x(g(t)) \geqq x(t-c)$ and thus $x(g(t)) / x(t) \geqq x(t-c) / x(t)$.

If case (2) applies, then exactly as in [1], we find $x(g(t)) / x(t) \geqq$ $k_{1}\left(k_{1}>0\right)$ for $t$ large.

Now suppose case (3) applies. Consider $\lim _{t \rightarrow \infty} x(t-c) / x(t)$ which is of the form $\infty / \infty$. Using L'Hopital's rule a sufficient number of times we obtain

$$
\lim _{t \rightarrow \infty} \frac{x(t-c)}{x(t)}=\cdots=\lim _{t \rightarrow \infty} \frac{x^{(n-k-1)}(t-c)}{x^{(n-k-1)}(t)}
$$

If $L$ (in case 3 ) is finite we are done since then

$$
\lim _{t \rightarrow \infty} \frac{x(t-c)}{x(t)}=\frac{L}{L}=1
$$

When $L=\infty$, then again using L'Hopital's rule we have

$$
\lim _{t \rightarrow \infty} \frac{x(t-c)}{x(t)}=\cdots=\lim _{t \rightarrow \infty} \frac{x^{(n-k)}(t-c)}{x^{(n-k)}(t)}
$$

If $M$ (in case 3 ) is positive again we are done since

$$
\lim _{t \rightarrow \infty} \frac{x(t-c)}{x(t)}=\frac{M}{M}=1
$$

However, if $M$ is zero we then claim that

$$
\lim _{t \rightarrow \infty} \frac{x^{(n-k-1)}(t-c)}{x^{(n-k-1)}(t)}=1
$$

since

$$
\lim _{t \rightarrow \infty}\left[x^{(n-k-1)}(t)-x^{(n-k-1)}(t-c)\right]=\lim _{t \rightarrow \infty} x^{(n-k)}(\xi) c=0, \quad t-c<\xi<t .
$$




$$
\left|\frac{x^{(n-k-1)}(t-c)}{x^{(n-k-1)}(t)}-1\right|=\left|\frac{x^{(n-k-1)}(t-c)-x^{(n-k-1)}(t)}{x^{(n-k-1)}(t)}\right|<\frac{\epsilon x^{(n-k-1)}\left(t_{1}\right)}{x^{(n-k-1)}\left(t_{1}\right)}<\epsilon
$$

where $t_{1} \geqq T$, is sych that $x^{(n-k-1)}\left(t_{1}\right)>0$. Summarizing we have $\lim _{t \rightarrow \infty} x(t-c) / x(t)=1$. Thus for $t$ large enough, $x(g(t)) / x(t) \geqq$ $x(t-c) / x(t)>\frac{1}{2}$.

Now letting $k_{2}=\min \left\{\frac{1}{2}, k_{1}\right\}$, we have $x(g(t)) / x(t) \geqq k_{2}$ for $t \geqq T_{1} \geqq T$ and

$$
\frac{\Phi(x(g(t)))}{\Phi(x(t))} \geqq \frac{\Phi\left(k_{2} x(t)\right)}{\Phi(x(t))}=k_{2}^{\beta} \frac{\Phi(x(t))}{\Phi(x(t))}=k_{2}^{\beta}=k
$$

Now suppose $x(t)$ is a nonoscillatory solution of (2) which is negative for $t \geqq T$. Again, pick $T$ large enough so that $x(t-c)<0$ for $t \geqq T$. Then (13) becomes

$$
x^{(n)}(t)=-f(t, x(g(t))) \geqq-b(t) \psi(x(g(t))) \geqq 0 \quad \text { if } \quad t \geqq T,
$$

and we find that $x(t)$ must satisfy one of the following:

(1) $\ddot{x}(t) \leqq 0, \dot{x}(t) \geqq 0$ for $t$ sufficiently large,

$$
\lim _{t \rightarrow \infty} \dot{x}(t)=0, \quad \lim _{t \rightarrow \infty} x(t)=L<0,
$$

(2) $\ddot{x}(t) \geqq 0, \dot{x}(t) \leqq 0$ for $t$ sufficiently large,

(3) $\ddot{x}(t) \leqq 0, \quad \dot{x}(t) \leqq 0$ for $t$ sufficiently large, with $x(t)$, $\dot{x}(t), \cdots, x^{(n-k-2)}(t)$ tending to $-\infty$ as $t \rightarrow \infty, x^{(n-k-1)}(t)$ decreasing to $L(-\infty \leqq L<0), x^{(n-k)}(t)$ increasing to $M(M \leqq 0)$, and $n^{(n-k+1)}(t)$, $\cdots, x^{(n-1)}(t)$ tending to zero as $t \rightarrow \infty$.

If case (1) applies, we have that $\lim _{t \rightarrow \infty} x(g(t))=L$ since $g(t) \geqq t-c$ and $x(t)$ is decreasing to $L<0$. Thus

$$
\lim _{t \rightarrow \infty} \frac{x(g(t))}{x(t)}=\frac{L}{L}=1
$$

In either case (2) or (3), $g(t) \geqq t-c$ implies $x(g(t)) \leqq x(t-c)$ and $|x(g(t))| \geqq|x(t-c)|$ with

$$
\frac{x(g(t))}{x(t)}=\left|\frac{x(g(t))}{x(t)}\right| \geqq\left|\frac{x(t-c)}{x(t)}\right|=\frac{x(t-c)}{x(t)} .
$$

If we now use arguments similar to those used when $x(t)>0$, we obtain the desired conclusion. 
THEOREM 4. If $g(t)$ is nondecreasing and satisfies (i) and $f(t, y)$ satisfies (ii)-(vii) of (12) and in addition

$$
\int_{0}^{\infty} t^{n-1} a(t) d t=\int_{0}^{\infty} t^{n-1} b(t) d t=+\infty
$$

then if $n$ is even each solution of (2), valid for large $t$, is oscillatory, while if $n$ is odd each solution of (2), valid for large $t$, is either oscillatory or it tends monotonically to zero together wth its first $n-1$ derivatives.

Proof. Suppose $x(t)$ is a nonoscillatory solution of (2), valid for large $t$. Assume $x(t)$ is eventually positive. Thus $x(t)>0$ and $x(g(t))>0$ for $t \geqq T$. From (2)

$$
x^{(n)}(t)=-f(t, x(g(t))) \leqq-a(t) \Phi(x(g(t))) \leqq 0 .
$$

Thus by Lemma $1 x^{(n-1)}(t)$ decreases to a nonnegative limit, so from (17) we obtain

$$
x^{(n-1)}(s) \geqq \int_{s}^{\infty} a(u) \Phi(x(g(u))) d u .
$$

Suppose case I of Lemma 2 holds. Then an integration of (18) $n-2$ times from $t$ to $\infty$ yields

$$
(-1)^{(n-2)} \dot{x}(t) \geqq \int_{t}^{\infty} \frac{(u-t)^{n-2}}{(n-2) !} a(u) \Phi(x(g(u))) d u .
$$

If $n$ is even, integrating (19) from $T$ to $t \geqq T$, we have

$$
x(t) \geqq \int_{T}^{t} \frac{(u-T)^{n-1}}{(n-1) !} a(u) \Phi(x(g(u))) d u .
$$

Since $\Phi$ is nondecreasing

$$
\Phi(x(t)) / \Phi\left[\int_{T}^{t} \frac{(u-T)^{n-1}}{(n-1) !} a(u) \Phi(x(g(u))) d u\right] \geqq 1 .
$$

If we now multiply (20) by

$$
\frac{(t-T)^{n-1}}{(n-1) !} a(t) \frac{\Phi(x(g(t)))}{\Phi(x(t))}
$$

and integrate from $r$ to $s$ we get, after a change of variable on the left 


$$
\begin{aligned}
\int_{R}^{s} \frac{d u}{\Phi(u)} & \geqq \int_{r}^{s} \frac{(t-T)^{n-1}}{(n-1) !} a(t) \frac{\Phi(x(g(t)))}{\Phi(x(t))} d t \\
& \geqq k \int_{r}^{s} \frac{(t-T)^{n-1}}{(n-1) !} a(t) d t
\end{aligned}
$$

where

$$
R=\int_{T}^{r} \frac{(u-T)^{n-1}}{(n-1) !} a(u) \Phi(x(g(u))) d u
$$

and

$$
S=\int_{T}^{s} \frac{(u-T)^{n-1}}{(n-1) !} a(u) \Phi(x(g(u))) d u
$$

Now if by an appropriate choice of $r$, we can make $R \geqq \alpha$, then the left hand side of (21) is bounded above for all $s>r$, hence $\int_{0}^{\infty} t^{n-1} a(t) d t<\infty$. If this is not possible then for all $r \geqq T$

$$
\begin{aligned}
\alpha & >\int_{T}^{r} \frac{(u-T)^{n-1}}{(n-1) !} a(u) \Phi(x(g(u))) d u \\
& \geqq \Phi(x(g(T))) \int_{T}^{r} \frac{(u-T)^{n-1}}{(n-1) !} a(u) d u
\end{aligned}
$$

and the result again follows.

If $n$ is odd, then (19) becomes

$$
-\dot{x}(t) \geqq \int_{t}^{\infty} \frac{(u-t)^{n-2}}{(n-2) !} a(u) \Phi(x(g(u))) d u \geqq 0 .
$$

So $x(t)$ decreases to a limit $L \geqq 0$. Suppose $L>0$. Then integrating (22) from $T$ to $\infty$,

$$
\begin{aligned}
x(T)>x(T)-L & \geqq \int_{T}^{\infty} \frac{(u-T)^{n-1}}{(n-1) !} a(u) \Phi(x(g(u))) d u \\
& \geqq \Phi(L) \int_{T}^{\infty} \frac{(u-T)^{n-1}}{(n-1) !} a(u) d u
\end{aligned}
$$

using the monotonicity of $\Phi$. But this implies $\int_{0}^{\infty} t^{n-1} a(t) d t<\infty$.

Now suppose that case II of Lemma 2 holds. Integrating (17) a sufficient number of times we have 


$$
x^{(n-k)}(t) \geqq \int_{t}^{\infty} \frac{(u-t)^{k-1}}{(k-1) !} a(u) \Phi(x(g(u))) d u
$$

Since $x^{(j)}(t)$ increases to $\infty, j<n-k-1$, there exists $t_{1} \geqq T$ such that $x^{(j)}(t)>0$ for $t \geqq t_{1}, j=0, \cdots, n-k-1$. Integrating (23) from $t_{1}$ to $t>t_{1}$,

$$
\begin{aligned}
x^{(n-k-1)}(t) & \geqq \int_{t_{1}}^{t} \int_{s}^{\infty} \frac{(u-s)^{k-1}}{(k-1) !} a(u) \Phi(x(g(u))) d u d s \\
& \geqq \int_{t}^{\infty} \frac{\left(u-t_{1}\right)^{k}-(u-t)^{k}}{k !} a(u) \Phi(x(g(u))) d u .
\end{aligned}
$$

So

$$
x^{(n-k-1)}(t)>\int_{t}^{\infty} \frac{\left(t-t_{1}\right)^{k}}{k !} a(u) \Phi(x(g(u))) d u .
$$

Integrating (24) successively $n-k-2$ times from $t_{1}$ to $t$ we obtain

$$
\dot{x}(t)>\int_{t}^{\infty} \frac{\left(t-t_{1}\right)^{n-2}}{(n-2) !} a(u) \Phi(x(g(u))) d u
$$

and integrating (25) from $t_{1}$ to $t$ gives

$$
x(t)>\int_{t_{1}}^{t} \frac{\left(u-t_{1}\right)^{n-1}}{(n-1) !} a(u) \Phi(x(g(u))) d u .
$$

Now the proof proceeds as in case I.

If $x(t)$ is a solution of (2), valid for large $t$, such that $x(t)<0$ for $t \geqq T$, the proof is the same except $a(t)$ and $\Phi(u)$ are replaced respectively by $b(t)$ and $\psi(u)$, and the sense of appropriate inequalities are changed. Q.E.D.

In the next theorem, condition (vi) of (12) is changed so that equation (2) includes the special case

$$
x^{(n)}+a(t) x^{\alpha}(g(t))=0, \quad 0 \leqq \alpha<1,
$$

the ratio of odd integers.

THEOREM 5. Let $g(t)$ satisfy (i) and $f(t, y)$ satisfy (ii)-(v) of (12). In addition suppose $f(t, y)$ satisfies (vii) there exist positive constants $\lambda_{0}, M, N$ and constants $\beta, \gamma$, where $0 \leqq \beta<1,0 \leqq \gamma<1$, such that 


$$
\begin{array}{ll}
\Phi(\lambda y) \geqq M \lambda^{\beta} \Phi(y), & y>0, \\
\psi(\lambda y) \leqq N \lambda^{\gamma} \psi(y), & y<0, \quad \lambda \geqq \lambda_{0}>0 .
\end{array}
$$

\section{Then if}

$$
\int_{t}^{\infty} t^{(n-1) \beta} a(t) d t=\int_{t}^{\infty} t^{(n-1) \gamma} b(t) d t=+\infty
$$

each solution of (2), valid for large $t$, is oscillatory when $n$ is even and is either oscillatory or tends to zero with its first $n-1$ derivative if $n$ is odd.

\section{REFERENCES}

1. J. S. Bradley, Oscillation theorems for a second-order delay equation, to appear.

2. L. E. El'sgol'ts, Introduction to the Theory of Differential Equations with Deviating Arguments, Holden-Day, Inc., San Francisco, London, Amsterdam, 1966.

3. I. T. Kiguradize, The problem of oscillations of solutions of nonlinear differential equations, J. Differential Equations, 3 (1967), 773-782.

4. J. W. Macki and J. S. W. Wong, Oscillation of solutions to second-order non-linear differential equations, Pacific J. Math., 24 (1968), 111-117.

5. Hiroshi Onose, Oscillatory property of ordinary differential equations of arbitrary order, J. Diff. Eqs. 'Vol., 7 (1970), 454-458.

6. Gerald H. Ryder and David V. V. Wend, Oscillation of solutions of certain ordinary differential equations of nth order, Proc. Amer. Math. Soc., 25 No. 3 (July 1970), 463-469.

7. Paul Waltman, A note on an oscillation criterion for an equation with a functional argument, to appear.

Received January 9, 1975. These results are part of the author's Ph.D. Thesis, written under the guidance of Dr. Gerald Ryder at Montana State University.

ForT LeWIS COLLEgE,

DURANGO,

COlORADO 81301 



\section{PACIFIC JOURNAL OF MATHEMATICS}

\section{EDITORS}

RICHARD ARENS (Managing Editor)

University of California

Los Angeles, California 90024

\author{
R. A. Beaumont \\ University of Washington \\ Seattle, Washington 98105
}

\section{J. DugundII}

Department of Mathematics

University of Southern California

Los Angeles, California 90007

D. Gilbarg and J. Milgram

Stanford University

Stanford, California 94305

\section{ASSOCIATE EDITORS}
E. F. BECKENBACH
B. H. NeumanN
F. WoLF
K. YoshidA

\section{SUPPORTING INSTITUTIONS}

\author{
UNIVERSITY OF BRITISH COLUMBIA \\ CALIFORNIA INSTITUTE OF TECHNOLOGY \\ UNIVERSITY OF CALIFORNIA \\ MONTANA STATE UNIVERSITY \\ UNIVERSITY OF NEVADA \\ NEW MEXICO STATE UNIVERSITY \\ OREGON STATE UNIVERSITY \\ UNIVERSITY OF OREGON \\ OSAKA UNIVERSITY
}

\author{
UNIVERSITY OF SOUTHERN CALIFORNIA \\ STANFORD UNIVERSITY \\ UNIVERSITY OF TOKYO \\ UNIVERSITY OF UTAH \\ WASHINGTON STATE UNIVERSITY \\ UNIVERSITY OF WASHINGTON \\ AMERICAN MATHEMATICAL SOCIETY
}

The Supporting Institutions listed above contribute to the cost of publication of this Journal, but they are not owners or publishers and have no responsibility for its contents or policies.

Mathematical papers intended for publication in the Pacific Journal of Mathematics should be in typed form or offset-reproduced (not dittoed), double spaced with large margins. Underline Greek letters in red, German in green, and script in blue. The first paragraph or two must be capable of being used separately as a synopsis of the entire paper. Items of the bibliography should not be cited there unless absolutely necessary, in which case they must be identified by author and Journal, rather than by item number. Manuscripts, in duplicate, may be sent to any one of the four editors. Please classify according to the scheme of Math. Reviews, Index to Vol. 39. All other communications should be addressed to the managing editor, or Elaine Barth, University of California, Los Angeles, California, 90024.

100 reprints are provided free for each article, only if page charges have been substantially paid. Additional copies may be obtained at cost in multiples of 50.

The Pacific Journal of Mathematics is issued monthly as of January 1966. Regular subscription rate: $\$ 72.00$ a year (6 Vols., 12 issues). Special rate: $\$ 36.00$ a year to individual members of supporting institutions.

Subscriptions, orders for back numbers, and changes of address should be sent to Pacific Journal of Mathematics, 103 Highland Boulevard, Berkeley, California, 94708.

PUBLISHED BY PACIFIC JOURNAL OF MATHEMATICS, A NON-PROFIT CORPORATION Printed at Jerusalem Academic Press, POB 2390, Jerusalem, Israel.

\section{Copyright (C) 1975 Pacific Journal of Mathematics All Rights Reserved}




\section{Pacific Journal of Mathematics

Vol. 60, No. $2 \quad$ October, 1975

Waleed A. Al-Salam and A. Verma, A fractional Leibniz q-formula ........... 1

Robert A. Bekes, Algebraically irreducible representations of $L_{1}(G) \ldots \ldots \ldots \ldots 11$

Thomas Theodore Bowman, Construction functors for topological

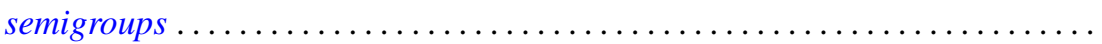

Stephen LaVern Campbell, Operator-valued inner functions analytic on the

closed disc. II .........................................

Leonard Eliezer Dor and Edward Wilfred Odell, Jr., Monotone bases in $L_{p} \ldots \ldots$.

Yukiyoshi Ebihara, Mitsuhiro Nakao and Tokumori Nanbu, On the existence of

global classical solution of initial-boundary value problem for

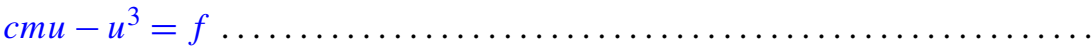

Y. Gordon, Unconditional Schauder decompositions of normed ideals of

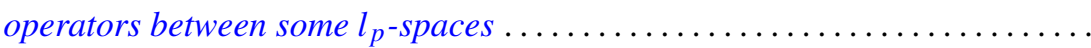

Gary Grefsrud, Oscillatory properties of solutions of certain nth order functional

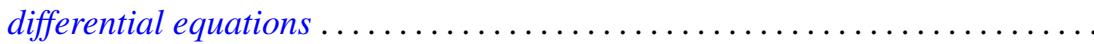

Irvin Roy Hentzel, Generalized right alternative rings ...................

Zensiro Goseki and Thomas Benny Rushing, Embeddings of shape classes of compacta in the trivial range .................................

Emil Grosswald, Brownian motion and sets of multiplicity . .

Donald LaTorre, A construction of the idempotent-separating congruences on a

bisimple orthodox semigroup .

Pjek-Hwee Lee, On subrings of rings with involution ...

Marvin David Marcus and H. Minc, On two theorems of Frobenius ...

Michael Douglas Miller, On the lattice of normal subgroups of a direct

product. .

Grattan Patrick Murphy, A metric basis characterization of Euclidean space

Roy Martin Rakestraw, A representation theorem for real convex functions ....

Louis Jackson Ratliff, Jr., On Rees localities and $H_{i}$-local rings ...

Simeon Reich, Fixed point iterations of nonexpansive mapping . .

Domenico Rosa, $B$-complete and $B_{r}$-complete topological algebras ...

Walter Roth, Uniform approximation by elements of a cone of real-valued

functions ....

Helmut R. Salzmann, Homogene kompakte projektive Ebenen

Jerrold Norman Siegel, On a space between $B H$ and $B_{\infty} \ldots$

235

Robert C. Sine, On local uniform mean convergence for Markov operators

James D. Stafney, Set approximation by lemniscates and the spectrum of an

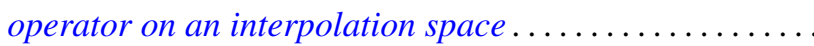

Árpád Száz, Convolution multipliers and distributions .......

Kalathoor Varadarajan, Span and stably trivial bundles ..........

Robert Breckenridge Warfield, Jr., Countably generated modules over

commutative Artinian rings....................... 